\title{
Money as health: a study of health status disparities among african americans of flint, michigan
}

\begin{abstract}
Choice theory has been used as an effective approach in the assessment and treatment of human behavior. It is particularly deployed in cases involving the clinical care of patients who may have chronic co-morbid conditions. ${ }^{1,2}$ Although choice theory explores how the personal choices of patients impact their health outcome, there are certain contexts in which health status cannot be simply attributed to maladaptive behaviors. ${ }^{1}$ This claim may seem counterintuitive to the basic tenets of the behavioral health enterprise, but a case can be made regarding how a patient's social economic status may predispose him/her to unwanted or unwarranted cycle of poor health status. In this article, the author examines the issue of poverty as a significant predictor of health status. By carefully reviewing relevant literature on the social economic status of African American residents of Flint, Michigan, publically available data suggests a correlation between poverty and the health status of this minority population. Given that a patient's economic means determine where he/she may reside, it is not enough to attribute related health disparities to the question of personal choices. The victims of the lead poisoning in Flint did not choose their health status. They were simply relegated to a potentially hazardous environment, which had direct implications for their health status.
\end{abstract}

Keywords: health disparity, poverty, leads poisoning, African, American, health status
Volume 8 Issue 3 - 2017

Chinedum Amadi

Arizona State University, USA

Correspondence: Chinedum Amadi, Arizona State University, 416 S. Elmwood Avenue Apt 3, Oak Park IL 60302, USA, Email chinedum.amadi@asu.edu

Received: September 02, 2017| Published: November 08, 2017

\section{Discussion}

The notion of money as health, too many including scholars, may seem scandalous. As may be apparent, even the rich may die young or may be vulnerable to certain kinds of terminal cancer conditions. Death is a certain equalizer: both the rich and the poor face its ultimate reality. Humans have sought to prolong their lives through innovative discoveries in the field of health sciences. These health-related researches do not usually include conquering death within their scope. Recently, some scholars have disseminated the idea of cheating death as reality. The notion of cheating death may be considered a form of denial or perhaps a raising of false hope. ${ }^{3}$ There is no such thing as cheating death. These experiences may have been narrow escapes from the grips of death. A person or group of persons cannot use money to buy immortality on planet earth. It cannot directly produce positive health behaviors in individuals in any population whatsoever. However, on the basis of Skinner's behaviorism, money can be used as a form of inducement or motivation in order to elicit positive responses in a person-for example exercising at a gym to get reward points. These points have monetary value and may then be used for the purchase of various goods and services. ${ }^{4}$ The argument here is that the idea of money as health is not without limitations or exclusions. Medical researchers cannot use money to change certain genetic markers in individuals, risk factors that can make them vulnerable to certain disease conditions. At best, health services bought with money may be used to either suppress or reduce the negative impact of these abnormal biomarkers. ${ }^{5}$ In popular culture, the common expression is that health is wealth. There is a grain of truth in this assertion. No doubt, the health status of a nation has serious implications in terms of both economic growth and military prowess. ${ }^{6}$ If a nation has a large population of sick citizens in various age brackets, this is likely to impact healthcare costs, especially in cases of rampant chronic conditions. ${ }^{7}$ The recruitment and subsequent retention of military personnel are contingent on their health conditions. This is why rampant obesity in the military-age population nationally may pose a serious threat to recruitment efforts in any branch of the US military. Combat readiness must then imply a keen attention to the health status of not only military personnel, but also their family members. In view of these and other unmentioned reasons, health can be considered wealth.

On the other hand, wealth may also be considered health. At the surface level, this position may appear counter-intuitive given the emphasis on health behaviors. Of course, positive health behaviors are necessary for both individual and population-health considerations. However, there are instances where health behaviors are not enough in themselves. ${ }^{8}$ This paper seeks to elucidate how a lack of economic empowerment can become a major source of health status disparities in minority populations. Although the subject of health disparities can be complex as well as broad, the scope of this current effort has been narrowed to investigating the direct and indirect connectedness of poverty to the issue of health disparities among African Americans in Flint, Michigan.

\section{Method}

This study was conducted using the Correlational approach. The researcher did not recruit any human subjects from the target population under review. There were no interviews or surveys conducted as part of the study. Publically available data sets were adapted for the purposes of analysis. For example, housing data on Flint was reviewed as an evidentiary basis of investigating the relationship between poverty and related health status disparity.

\section{What is health disparity?}

As the concept of health disparity can mean various things to different groups of people, it is important to provide a working definition that is appropriate for this level of discourse. Braveman ${ }^{9}$ cited Healthy People 2020 to have defined health disparity as 
"a particular type of health difference that is closely linked with economic, social, or environmental disadvantage" (p.1). It is pertinent to note that these forms of disadvantage or inequality are often caused by institutionalized oppression. The basis for this oppression may encompass such variables as race, gender, religion, sexual orientation, disability, socio-economic status, ethnicity, and place of residence. ${ }^{9}$ For the purposes of this study, the focus will be on analyzing how injustice based on the variables of race, socio-economic status, and geographical location has systematically produced adverse health outcomes for the African American population in Flint. The target population under investigation is a minority group within the United States. ${ }^{10}$ For some scholars, the term minority as currently used may be arbitrary and problematic. ${ }^{11}$ It has been used appropriately in this discussion to describe the African American population in Flint. There is both historical and contemporary evidence documenting the marginalization of African Americans. The question of racial politics will be given more attention in a separate section in this paper. Also, the issue of environmental degradation or neglect is critical in placing the experiences of the African American community in Flint within the purview of health disparities. Indeed, the current case of lead poisoning in the geopolitical jurisdiction of Flint is a visible expression of the interconnectedness of race, power, money, and health disparities. Defining what constitutes health disparity is not without controversy. There are various schools of thought or theoretical approaches in studying health disparities. These schools of thought provide varying shades of opinion as to the causes and effects of health disparities. Sometimes, these perspectives are heavily influenced by ideological tenets rather than verifiable evidence ${ }^{5}$ This divergence of views results in the use of different words to describe the same concept in public health literature. Some of the terms commonly used interchangeably with 'health disparity' include 'health inequalities' and 'health inequities.' These words carry certain nuances and are used by different groups in varying contexts. ${ }^{8}$ While differences in health status may result from both genetic and environmental factors, the critical measure for determining valid cases of disparity is 'causality.' There is little or nothing anybody or institution can do about changing a person's or a group's genetic history. However, the government and other vital stakeholders can create policies and programs to reduce poverty and/ or environmental degradation. Health disparity occurs in the contexts of unjust deprivations-whether conscious or unconscious-that result in significant health outcomes amongst various racial/ethnic groups. ${ }^{12}$ The scope of this paper neither includes illusions of 'cheating death' nor grandiose ideas of zero poverty. If health disparities occur and do become prevalent due to avoidable, social circumstances as in Flint, the solution to reducing the prevalence rate of health-related disparities must then lie in addressing the social as well as ecological factors that create them. As this current effort will show, money is a major variable in any decision regarding where a person or group of persons live. No matter how positive-minded a person may be, he/she is limited to living in the neighborhoods that his/her economic means can afford.

Granted that the argument can be made that moving into a neighborhood has an element of choice, it ought to be noted that any such choice must be within the framework of economic means. If money is the base that determines whether a person or group of persons live in either a polluted or non-polluted environment, policy makers and all vital stakeholders cannot modify or reform the superstructure without due consideration as to the nature of the base. The superstructure as used here represents health-related outcomes. ${ }^{13}$ In the case of the African American residents of Flint, living therearguably a result of economic means-opened the window to a higher risk of exposure to environmental pollution with all the concomitant health complications (Figure 1).

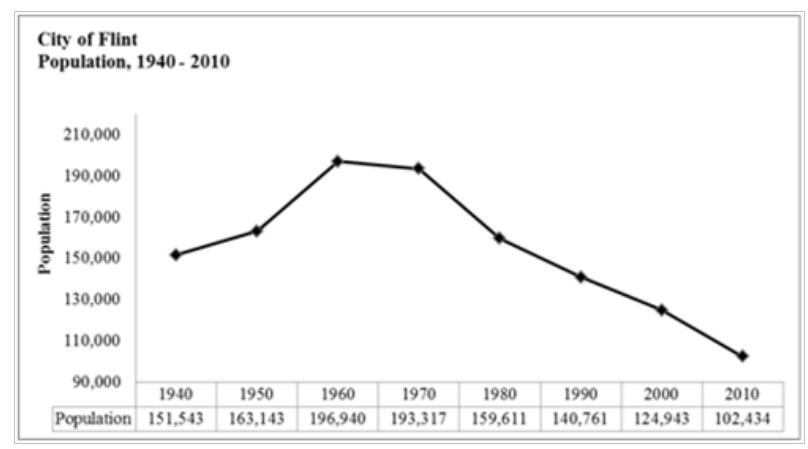

Figure I City population.

Source:Adapted from Scorsone \& Bateson. ${ }^{14}$

\section{Demographic background}

The City of Flint is located in Genesee County in the State of Michigan. ${ }^{14}$ Jacob Smith founded it in 1819 as a trading post. The city is situated along the Flint River, about 60 miles $(100 \mathrm{~km})$ northwest of Detroit. Contrary to its current state of neglect, it used to be a popular industrial hub for auto manufacturing. Buick Motor Company (which later merged with General Motors) had established a plant there in 1903. With the merger of Buick Motor Company, General Motors became the dominant car manufacturing company in Flint. The city flourished with the business growth of the auto industry. ${ }^{15}$ However, the subsequent relocation of the auto plants from Flint to other locations brought unintended consequences to the local economy of Flint. One direct consequence of the falling economic opportunities was the flight of white residents from the city to other prosperous communities. ${ }^{14}$ Having provided a brief historical overview of Flint, it is important to show its current demographical data in terms of race, employment, income, and health indicators (Figure 2). Based on figures from the 2010 US census data, the current population of Flint is about 102, 434 residents..$^{14}$ Evidence from the 2010 census data indicates that there were 57,939 African American residents in Flint. This figure represented a 3.3\% increase from the census data in 2000. On the basis of this data, the African American ethnic group constituted about $56.6 \%$ of the entire Flint population. On the other hand, the 2010 census data indicated that the total number of Caucasian Americans in Flint was 38, 328, which represented a $4 \%$ decrease from the 2000 census data. This evidence suggests that the failing economy in Flint had resulted in the flight of its white residents, who may have moved out to more economically prosperous neighborhoods. Living in a geographical location with few or no opportunities may be inadvisable, but not uncommon. The temptation may be to hastily conclude the persons trapped in less prosperous neighborhoods are lazy. In other words, these are the classic examples of welfare dependents ("Welfare dependent," 2015) (Figure 3). As earlier posited, the choice of residential mobility is contingent on economic means. Whereas some of the white residents were able to move, a greater number of Flint residents-predominantly blacksremained. In fact, the data shows a reverse trend for African American residents. There was an increase in the number of African Americans in Flint, even in the face of dwindling economic opportunities. The only rational reason for this choice is economic means. Maybe, the failing local economy had resulted in lower housing value, which would make Flint paradoxically attractive to low-income earners in the African American population. ${ }^{14}$ 


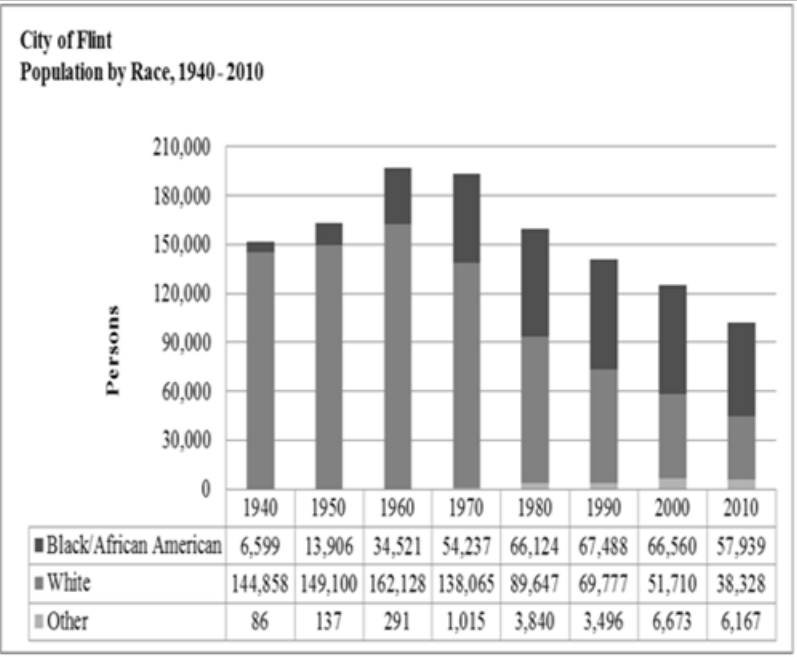

Figure 2 Population by race.

Source:Adapted from Scorsone \& Bateson. ${ }^{14}$

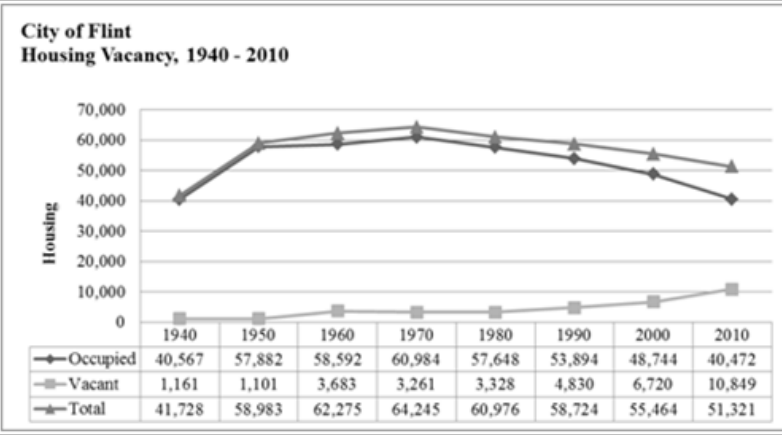

Figure 3 Housing vacancy.

Source:Adapted from Scorsone \& Bateson. ${ }^{14}$

\section{Health disparity and geographical affinity}

On the surface, one may not readily see the connection between a group's residential location and health disparity. However, there is evidence in literature to suggest that environmental pollutants, whether by water or air, can make the residents of a neighborhood susceptible to certain disease conditions. ${ }^{16}$ It is not uncommon for many low-income earners to resign to living in relatively impoverished neighborhoods in a desperate effort to avoid homelessness. Of course, housing is one the basic human needs. ${ }^{17}$ It therefore makes sense that low-income earners in the African American community in Flint would choose to stay there in the face of job losses. The job losses had had a direct impact on home values in Flint. Scorsone \& Bateson ${ }^{14}$ reported, "The City of Flint's jobless rate for the 2010 annual reporting period was among the highest in the state at $23.2 \%$. Countrywide unemployment was at $13.7 \%$. In early 2011 , the County's unemployment rate was at $10.8 \%$ ranking it 41 out of 83 counties in the State of Michigan" (p.6). The City of Flint had recently gained national and perhaps international notoriety as a consequence of the lead-poisoning scandal. High and unsafe levels of lead had resulted in the contamination of the drinking water from the Flint River. ${ }^{18}$ The task force's final report noted, "The Flint water crisis is a story of government failure, intransigence, unpreparedness, delay, inaction, and environmental injustice" (p. 5). All relevant stakeholders in Flint may have possibly averted the current crisis given the risk analysis earlier projected in Scorsone \&
Bateson. ${ }^{14}$ Perhaps, the government-at all levels-may not have paid adequate attention to the impending public health hazard in Flint due to its racial/ethnic makeup. African Americans constitute the majority of the residents in the city. The reason for this majority correlates with the quest for affordable housing, given that available data show fallen home values in Flint as of the year 2011. 'Environmental injustice' as determined above is an appropriate expression for portraying the systemic neglect and degradation of a neighborhood in which most residents may be poor. The African American population in Flint has peculiar health disparities that are inextricably tied to the group's geographical location. For example, as of October 2015 there was evidence to suggest that a significant number of Flint children had already been exposed to lead poisoning. Flint Water Advisory Task Force ${ }^{18}$ concluded that "excessive and likely harmful lead exposure already has occurred for hundreds and perhaps thousands of children in Flint, and it now responsibility of the Michigan Department of Health and Human Services (MDHHS) to follow up with comprehensive secondary prevention. The MDHHS reports that about 200 children in Flint are known to have had childhood levels $>5$ micrograms/ deciliter when they were tested since April 2014 (the month of the water switch to the Flint River)" (p. 32). Clearly, this exposure to lead contaminated water is the cost of being poor and living in an impoverished neighborhood. In the face of available evidence, any attempt to remedy the lead-related health complications in Flint ought to address the issue of disproportionate poverty amongst African Americans in Flint.

\section{Racial politics and health disparity}

The data from Scorsone \& Bateson ${ }^{14}$ suggested that as the local economy of Flint was beginning to fail around 2010, a significant percentage of the white residents in Flint began to move out of the city. It appears that the main reason for this exodus out of the city, by some white residents, was due to economic reasons. These residents had to move to other places where they could find jobs. While the choice to relocate for the sake of finding new employment is appropriate, such a decision does not occur without other relevant considerations. It would be unrealistic to contemplate moving out to a more prosperous neighborhood if a person does not have the needed financial support to buy or rent a new home. Unlike some of the white residents who had made a decision to move out of Flint, many African Americans remained in the city at a time of high unemployment rate. Indeed, there is evidence supporting the fact that more African Americans moved into Flint around 2010. ${ }^{14}$ The high concentration of many low-income earners, especially from a minority group, in a given neighborhood as in the Flint case, can lead to residential segregation. Williams \& Mohammed $^{19}$ have argued that residential segregation has the potential to negatively impact a group's earning power. Accordingly, the less income a group earns, the higher the risks of living in potentially hazardous neighborhood. The Flint saga illustrates how the issue of money or economic power can either be a protective factor or risk factor for a group. The Africans American residents of Flint, to a great extent, live there as a result of earning low income. When the government or its designated authorities ignore the legitimate right of residents to both clean air and water, perhaps due to both racial and/or class considerations, then the residents pay a price in the form of health disparities. For example, in its final published report, Flint Water Advisory Task Force ${ }^{18}$ listed the possible effects of exposure to lead poisoning as follows:

One of the most concerning aspects of lead exposure is that once it has been deposited in the nervous system, lead cannot be removed. The impact of lead poisoning on neurological development is 
permanent. Recent research has indicated that, with each 1 microgram per deciliter increase in blood lead level, children demonstrate decreasing performance on intelligence tests. (p. 23) Historically, African Americans have experienced and do experience racism. The impact of both overt and covert racism on African Americans has been well documented in literature. One outstanding example of institutionalized racism, and in sense violence, against African Americans was the Tuskegee Study. ${ }^{20}$ Race relations have improved in the United States since Tuskegee. This is exemplified by the election of Barack Obama as president. However, the shadows of the past are still visible, even if many choose to ignore them. And the recent 'intransigence' on the part of public officers in Michigan (when African Americans and others were slowly being poisoned) has the unintended effect of reminding the black residents of not only Tuskegee, but also slavery. Such conduct on the part of public officials may send the subtle message to these black residents, particularly, that their health and well-being do not matter. Notwithstanding public evidence, it is possible that there are still those-they have a right to their opinion-who would see no racial nuances in the current plight of African Americans in Flint. It is this sense of invisibility that is responsible for the neo-protest movement called Black Lives Matter. ${ }^{21}$ There is evidence from public medical data that a significant number of children in Flint have been exposed to excessive and harmful levels of lead. ${ }^{18}$ Although this researcher has no evidentiary data on the racial identities of the affected children, it will not be unreasonable to deduce that a large percentage of the children may be African American by ethnicity. This projection is based on the census data shown in another section. The effects of institutionalized racism are already reflected in the performance of minority children in the public school system, especially in cities such as Flint, where educational growth may not be a priority. As noted earlier, the most devastating impact of lead exposure to human health is neurological damage. For these affected children, any permanent neurological damage has enormous implications for school performance, social skills, and indeed overall health status. As if the burden of being black is not enough, these children will grow up facing the social stigma associated with developmental disabilities.22

The health-related burden produced by living in a relatively impoverished or systematically neglected area as Flint, is not a matter rooted in either individual or group health behaviors. It would be rather simplistic to reduce the question of systemic social and environmental injustice to health behaviors. There is a valid basis for advocating positive, health-related choices that can change the prevalence rate of certain morbid conditions in varying populations. For example, teaching adolescents how to incorporate regular physical activities as a weekly routine may result in a corresponding decrease in the prevalence rate of obesity, and consequently reduce the risks of diabetes mellitus. ${ }^{23}$ However, when a group of people is relegated to the Flints of this earth solely or partially as a result of poverty, the answer must then lie in addressing the policies that create 'gaps' for oppression and/or 'inequity.' The African American children and their parents, whose hopes and aspirations have been perhaps permanently changed, did not opt for drinking lead-contaminated water from the Flint River. The attendant health disparities resulting from waterrelated exposure to lead poisoning is socially created, avoidable, and may possibly reignite the unpleasant memories of Tuskegee. ${ }^{20}$

\section{Conclusion}

In this paper, the issue of health status disparities amongst the African American residents of Flint was discussed. Based on available data, it appears that many black residents in Flint were attracted to the city mainly for the reason of affordable housing. These residents remained in Flint in spite of the reality of job losses. For these African American residents, housing was critically important for their daily survival. Notwithstanding the benefits of finding affordable housing in a somewhat impoverished neighborhood, there are also health-related risks. It then becomes a matter of cost-benefit analysis. Unfortunately, in most cases the costs associated with living in a place like Flint far outweigh the benefits. Given that exposure to lead has far-reaching public health ramifications, there should be no room for creating a scenario where residents become victims of palpable environmental injustice. A large segment of the African American population in Flint has experienced and do experience health disparities as a result of being poor. If money can be considered a principal factor, which determines voluntary or involuntary assignment to a neighborhood, then there can be no realistic solution to health disparities without addressing the question of cyclical poverty.

\section{Acknowledgements}

The researcher is grateful to Dr. CR Macchi, Associate Chair of Internship Programs in the Doctor of Behavioral Health Program at Arizona State University. His mentorship was a critical part of this research work.

\section{Conflict of interest}

The author declares no conflict of interest while completing the study.

\section{Funding}

None.

\section{References}

1. Holman D, Borgstrom E. Applying social theory to understand healthrelated behaviours. Medical Humanities. 2016;42(2):143-145.

2. Melnyk BM, Small L, Morrison-Beedy D, et al. Mental health correlates of healthy lifestyle attitudes, beliefs, choices, and behaviors in overweight adolescents. J Pediatr Health Care. 2006;20(6):401-406.

3. Tsou A, Arthur C. Cheating death and the dangers of false hope. The Lancet. 2010;375(9723):1337-1338.

4. Purcell JQ, Gernes R, Stein R, et al. A systematic review of financial incentives for dietary behavior.JAcad Nutr Diet. 2014;114(7):1023-1035.

5. Krieger N. Stormy weather; Race, gene expression, and the science of health disparities. Am J Public Health. 2005;95(12):2155-2160.

6. Cohen DB, Cook AH. At the intersection of public health and national security : The evolution of smallpox policy in the Clinton G.W. Bush administration. Politics \& Policy. 2006;34(1):156-194.

7. Christensen CM, Grossman JH, Hwang J. The Innovator's Prescription: A disruptive solution for health care. (1st edn), McGraw Hill, USA. 2009. p. 1-496.

8. Carter-Pokras O, Baquet, C. What is "Health disparity"? Public Health Reports. 2002;117(5):426-434.

9. Braveman P. What are health disparities and health equity? We need to be clear. Public Health Rep. 2014; 129Suppl 2:1-5-8.

10. Pollard MK, O'Hare WP. America's racial and ethnic minorities. Population Bulletin. 1999;54(3):1-52.

11. Purnell L. Minority groups: an outdated concept?. Journal of Advanced Nursing. 2004;48(5):429.

12. Herbert P, Sisk JE, Howell EA. When does a difference become a disparity? Conceptualizing racial and ethnic disparities in health. Health Aff (Millwood). 2008;27(2):374-382. 
13. Nobleman R. Addressing access to justice as social determinant of health. Health Law Journal. 2014;21:49-74.

14. Scorsone E, Alan Mallach. Long-term crisis and systemic failure; Taking the fiscal stress of America's older cities. Case study. Michigan State University, USA. 2011.

15. Flint, Encyclopedia Britannica, Michigan, USA. 2016.

16. Morello-Frosch R, Lopez R. The riskscape and the color: Examining the role of segregation in environmental health disparities. Environ Res. 2006;102(2):181-196.

17. Mulroy A, Ewalt P. Editorial: Affordable housing: A basic need a social issue. Social Work. 1996;41(3):245-249.

18. Flint Water Task Force (2016).
19. Williams DR, Mohammed SA. Discrimination and racial disparities in health: Evidence and needed research. J Behav Med. 2008;32(1):20-47.

20. Shavers VL, Lynch CF, Burmeister LF. Knowledge of the Tuskegee study and its impact on the willingness to participate in medical research studies. J Natl Med Assoc. 2000;92(12):563-572.

21. Shor F. "Black lives matter": Constructing a new civil rights and black freedom movement. New Politics. 2015;15(3):28-32.

22. Werner S. Stigma in the area of intellectual disabilities: Examining a conceptual model of public stigma. Am J Intellect Dev Disabil. 2015;120(5):460-475.

23. Marcovecchio ML, Chiarelli F. Micro vascular disease in children and adolescents with type 1 diabetes and obesity. Pediatric Nephrology. 2011;26(3):365-375. 